\title{
Análise estrutural do sistema de grabens do Rio Tocantins, borda oeste da Bacia do Parnaíba (estados do Tocantins, Pará e Maranhão - Brasil)
}

\author{
Structural analysis of the Tocantins river graben system, western border of the Parnaiba \\ Basin (states of Tocantins, Pará and Maranhão - Brazil)
}

\author{
Kauê Seoane Souza1, Emanuel Ferraz Jardim de Sá1,2 e Fernando César Alves da Silva ${ }^{1,2}$ \\ ${ }^{1}$ Universidade Federal do Rio Grande do Norte - UFRN, Programa de Pós-graduação em Geodinâmica e Geofísica, \\ Campus Universitário, CP 1596, Lagoa Nova, CEP 59078-970, Natal, RN, Brasil (kaueseoanes@gmail.com) \\ 2Universidade Federal do Rio Grande do Norte - UFRN, Departamento de Geologia, Natal, RN, Brasil (emanuel@ccet.ufrn.br; \\ fernando@geologia.ufrn.br)
}

Recebido em 6 de junho de 2016; aceito em 11 de novembro de 2016

\begin{abstract}
Resumo
A borda oeste da Bacia do Parnaíba apresenta estruturas que a diferenciam do contexto em outras regiões na bacia. Destacam-se duas estruturas do tipo graben (Araguaína e Muricizal), que compõem o sistema de grabens em estudo, a primeira já no interior da bacia, a segunda implantada diretamente sobre o embasamento cristalino (Faixa Araguaia). Nas bordas do graben principal (Araguaína), as formações Motuca e Pedra de Fogo são balizadas por falhas normais ou normais oblíquas sinistrais. Mais a sul, na região de Palmas-Miracema do Tocantins, o Grupo Serra Grande, a Formação Pimenteiras e o embasamento cristalino estão em contato por falhas normais. O segundo graben, localizado a oeste do principal, também acomoda a Formação Motuca e unidades sotopostas, possuindo a mesma orientação. A análise de imagens SRTM auxiliou na cartografia dos fotolineamentos, dos grabens e, associada aos dados de campo, permitiu a proposição de três eventos deformacionais $\left(\mathrm{D}_{1}, \mathrm{D}_{2}\right.$ e $\left.\mathrm{D}_{3}\right)$. A orientação $\mathrm{N}-\mathrm{S}$ das falhas envolve uma variação de $20^{\circ}-30^{\circ}$ para $\mathrm{E}$ ou W, controlada pelas anisotropias do embasamento cristalino nesta borda da bacia, relacionadas à Faixa Araguaia. Falhas de regime normal e normal sinistral evidenciam uma distensão NE durante a formação dos grabens (evento $\mathrm{D}_{1}$ ). A idade mínima para $\mathrm{D}_{1}$ é estimada no intervalo Permo-Triássico, baseada nas relações estruturais e estratigráficas. Na região norte do mesmo, fotolineamentos E-W/ENE controlam o alojamento de basaltos e diabásios eojurássicos da Suíte Mosquito (evento $\mathrm{D}_{2}$ ), que interceptam as estruturas do graben principal. A distensão NNE na Suíte Mosquito e falhas normais ou transcorrentes exibindo distensão NW (evento $\mathrm{D}_{3}$ ) são tentativamente correlacionadas aos eventos de abertura do Atlântico Central e Sul, respectivamente.
\end{abstract}

Palavras-chave: Bacia do Parnaíba; Sistema de grabens; Estruturas distencionais.

\begin{abstract}
The western border of the Parnaíba Basin displays structures that differentiate it from those in other regions of the basin. Two graben structures can be highlighted (Araguaína and Muricizal), which compose the graben system in this study, the first one inside the basin, and the second implanted directly on the crystalline basement (Araguaia Belt). Along the borders of the main graben (Araguaína), the contacts between the Motuca and Pedra de Fogo formations and older units are defined by normal and sinistral normal-oblique faults. Further south, in the Palmas-Miracema do Tocantins region, the contacts between the Serra Grande Group, the Pimenteiras Formation and the crystalline basement follow normal faults. The westerly secondary graben also hosts the Motuca Formation and shows the same N-S orientation. The analysis of SRTM images allowed to map the photolineaments, the graben borders and, associated with field data, supports the proposition of three deformational events $\left(\mathrm{D}_{1}, \mathrm{D}_{2}\right.$ and $\mathrm{D}_{3}$ ). The N-S fault orientation involves a $20^{\circ}$ to $30^{\circ}$ of variation to $\mathrm{E}$ or $\mathrm{W}$, which is controlled by anisotropies of the crystalline basement related to the Araguaia Belt. Along the main graben, normal and normal-sinistral faults point to a NE-trending extension ( $D_{1}$ event). The minimum age for $D_{1}$ is estimated to be in the Permo-Triassic interval, based on structural and stratigraphic relationships. To the north, E-W/ENE photolineaments controlled the emplacement of the Eojurassic basalts and diabases of the Mosquito Suite ( $\mathrm{D}_{2}$ event), overprinting the N-S structures of the grabens. NNE structures in the Mosquito Suite and normal or transcurrent faults recording NW distension ( $\mathrm{D}_{3}$ event) are younger and tentatively correlated to the opening of the Central and South Atlantic, respectively.
\end{abstract}

Keywords: Parnaíba Basin; Graben system; Extensional structures. 


\section{INTRODUÇÃO}

A Bacia do Parnaíba (doravante abreviada como BPar, Figura 1) insere-se no contexto evolutivo das sinéclises paleozoicas brasileiras (Almeida e Carneiro, 2004), cujo arcabouço estrutural é relativamente simples. Contudo, a borda oeste da BPar e as estruturas ali presentes se distinguem do contexto regional da bacia por definirem grabens, conforme mapeado nas folhas Tocantins, Araguaia, Teresina e São Francisco (CPRM, 1:1.000.000) e pelos trabalhos de Faraco et al. (2004a, 2004b) e Vasconcelos et al. (2004a, 2004b). Tais feições estruturais também foram referidas em dissertações (Abreu, 1978; Gorayeb, 1981), mas sem caracterização detalhada, em termos de sua evolução e relações tectonoestratigráficas. Um graben menor a oeste da BPar, isolado no embasamento cristalino, segue o alinhamento N-S da Faixa Araguaia e do graben principal (Araguaína), tendo sido denominado por Souza (2016) de Graben do Muricizal.

O preenchimento desse graben ocidental foi inicialmente interpretado por Abreu (1978) como uma molassa brasiliana e designada como Formação Rio das Barreiras. Posteriormente, Araújo (2001) atribuiu idade Permiana-Eotriássica para a mesma, enquanto que Faraco et al. (2004a) admitiram uma

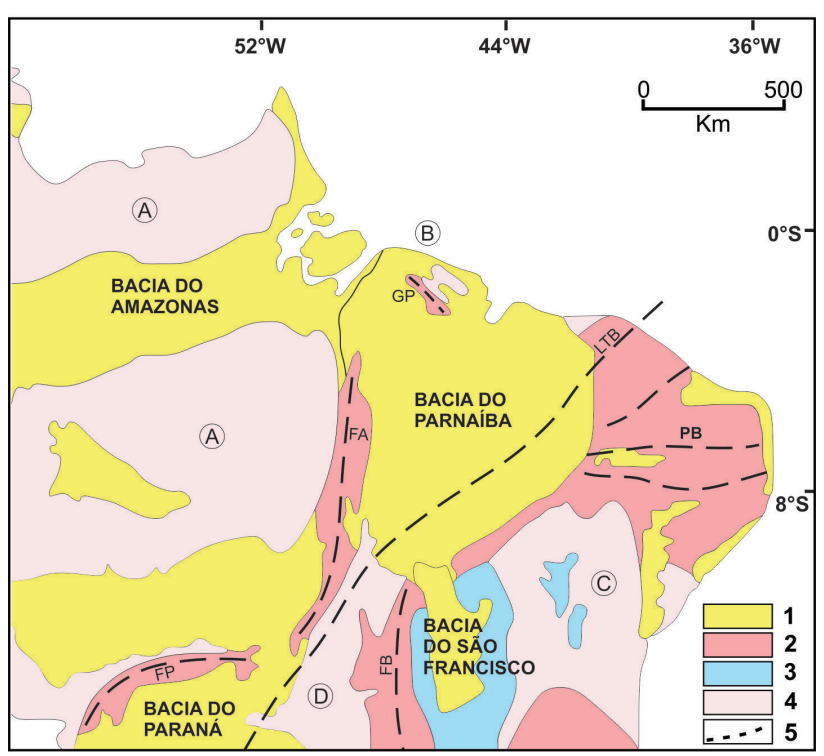

Figura 1. Esboço tectônico da porção centro-norte do Brasil. 1. Coberturas Fanerozóicas; 2. Faixas de Dobramentos Brasilianas: GP - Gurupi; FA - Faixa Araguaia; FB - Faixa Brasília e FP - Faixa Paraguai; LTB - Lineamento Transbrasiliano; PB - Província Borborema. 3. Cobertura Cratônica Bambuí. 4. Crátons Brasilianos: (A) Amazônico; (B) São Luís; (C) São Francisco; (D) Maciço Goiano. 5. Em tracejado, outros lineamentos brasilianos (compilado de Sadowski e Cruz Campanha, 2004). idade Creatácea. Finalmente, Souza (2016) correlacionou esses sedimentos à Formação Motuca, de idade Eotriássica.

A Faixa Araguaia (doravante abreviada como FA) apresenta-se estruturada na direção N-S (Figura 1), com aproximadamente $1000 \mathrm{~km}$ de extensão e largura variando entre 50 a $150 \mathrm{~km}$. Esta megaestrutura constitui-se por associações de rochas ígneas e metamórficas relacionadas ao Ciclo Brasiliano. Zonas de cisalhamento transcorrentes de direção NW-SE também fazem parte desse arcabouço, as quais seguem a direção dos lineamentos Carajás e Iriri-Martírios (Herz et al., 1989). É evidente o controle do sistema de grabens N-S pelo trend da FA.

Este trabalho apresenta uma caracterização estrutural da borda oeste da BPar com uma proposta para a sua evolução, contribuindo para o conhecimento da bacia em termos estruturais. A utilização de imagens de sensor remoto (SRTM - Missão Topográfica de Radar Transportado da NASA), somadas a campanha de campo ao longo dos grabens, auxiliou no mapeamento das principais estruturas.

\section{CONTEXTO GEOLÓGICO REGIONAL}

\section{Embasamento cristalino, megaestruturas e limites da Bacia do Parnaíba}

O embasamento da Bacia do Parnaíba (Figura 1) é composto por rochas metamórficas, ígneas e sedimentares pertencentes aos crátons São Francisco e São Luís, bem como aos terrenos afetados pela orogênese Brasiliana, lateralmente expostos (e inferidos no seu interior) nas províncias estruturais Tocantins e Borborema, além da Faixa Gurupi (Cordani et al., 2009).

A BPar está sobreposta a megaestruturas do seu embasamento cristalino que, em parte, afloram em regiões adjacentes, tais como o Lineamento Transbrasiliano, com direção NE-SW, e a Faixa Araguaia, com direção N-S, as quais influenciaram na estruturação da bacia, na nucleação de falhas e no controle de eixos deposicionais paleozoicos (Góes, 1995).

A BPar é delimitada por estruturas que incluem, ao norte, o Arco Ferrer-Urbano Santos; ao sul, o Arco São Francisco; a noroeste, o Arco do Capim e, a oeste, o "Lineamento Tocantins-Araguaia" (Cunha, 1986).

\section{A Bacia do Parnaíba: evolução Tectono-Estratigráfica Paleozoica-Mesozoica}

A Bacia do Parnaíba (ou Província Parnaíba no sentido de englobar outras bacias, além da referida, como proposto por Góes, 1995) possui cerca de $600.000 \mathrm{~km}^{2}$ de área e até $3.500 \mathrm{~m}$ de espessura sedimentar no seu depocentro, e forma poligonal levemente alongada na direção NNE (Figura 2). A principal etapa de seu desenvolvimento está relacionada 


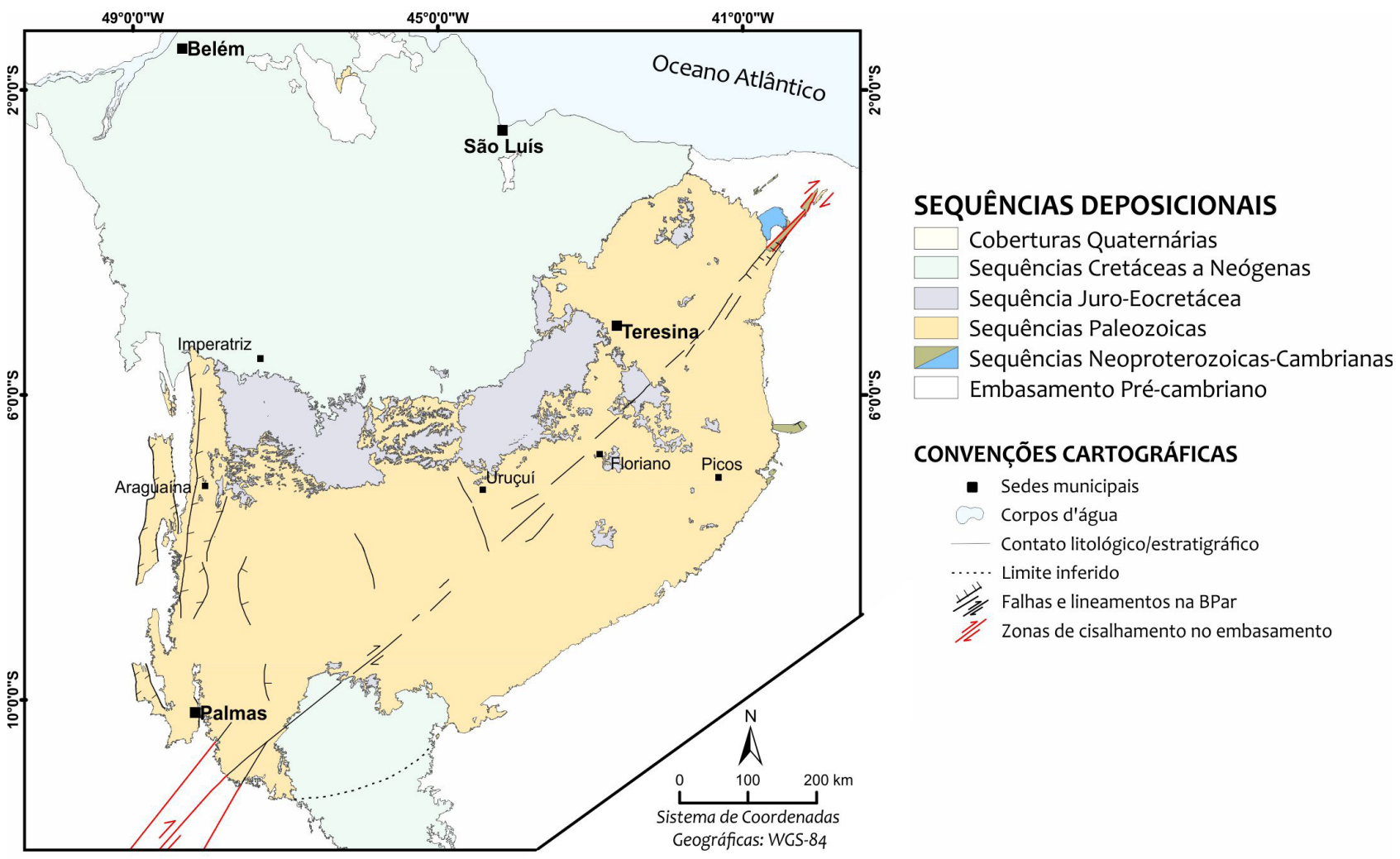

Figura 2. Delimitação da Província Parnaíba, com individualização das principais sequências estratigráficas. Foram representados esquematicamente os traços do Lineamento Transbrasiliano (LTB) e dos grabens em estudo, também com base nas referências citadas (compilado de Faraco et al., 2004a, 2004b; Vasconcelos et al., 2004a, 2004b).

ao estágio de estabilização da Plataforma Sul-Americana (Almeida e Carneiro, 2004).

Em termos de registro estratigráfico a bacia apresenta uma sucessão de rochas sedimentares, além de suítes magmáticas, englobadas em quatro sequências (Vaz et al., 2007; Figura 2). As unidades mais antigas incluem as sequências Siluriana (representada pelas rochas siliciclásticas de sistemas fluviais e pelitos plataformais do Grupo Serra Grande), Mesodevoniana-Eocarbonífera (representada pelas rochas siliciclásticas finas de sistemas plataformais do Grupo Canindé), e Neocarbonífera-Eotriássica (representada por depósitos clástico-evaporíticos do Grupo Balsas).

A partir do Eojurássico, mudanças significativas ocorreram na bacia, incluindo o alojamento dos diabásios e basaltos da Suíte Mosquito. Este evento é correlacionado à abertura do Atlântico Central, sendo proposto que a carga exercida pelas rochas ígneas teria gerado espaço para a deposição da Formação Pastos Bons, compondo a Sequência Jurássica (Góes, 1995; Vaz et al., 2007). Durante o Eocretáceo, com o início dos processos de formação do oceano Atlântico Sul, ocorreu um novo evento magmático básico (a Suíte Sardinha) e a deposição da Sequência Cretácea, formada por depósitos continentais e, a partir do Aptiano, sucessões marinhas e costeiras, estas ocorrendo na porção centro-norte da bacia (Figura 2; Vaz et al., 2007).

\section{MÉTODOS DE TRABALHO}

O estudo iniciou com os levantamentos de dados bibliográficos da região estudada e a análise de macroestruturas através de imagens digitais SRTM (Missão Topográfica de Radar Transportado da NASA). A etapa de campo envolveu a aquisição e coleta de dados estruturais e estratigráficos, com enfoque nas rochas sedimentares e na Suíte Mosquito, sendo que esta última possui boa distribuição na área de estudo. Foi utilizado um mapa geológico com a base cartográfica do Serviço Geológico do Brasil (folhas da CPRM em escala 1:1.000.000; Faraco et al., 2004a, 2004b; Vasconcelos et al., 2004a, 2004b).

\section{Análise de imagens orbitais}

As imagens digitais SRTM, com resolução espacial de 30 metros (adquiridas no site da USGS e com referencial planialtimétrico WGS 84), foram utilizadas na cartografia de fotolineamentos (aqui entendidos como traços de estruturas 
descontínuas, falhas e fraturas) na porção oeste da BPar e sua adjacência na Faixa Araguaia, bem como das fotolineações (traços de estruturas contínuas, mais comumente foliações) nesta última. Em geral, os fotolineamentos observados acompanham a direção N-S da FA e delimitam os grabens, objeto deste estudo. As fotolineações N-S são interceptadas por estruturas mais discretas NW e NE, definidas como zonas de cisalhamento transcorrentes dúcteis nos mapas da CPRM (Araújo, 2001). Imagens extraídas através do software Google Earth também foram utilizadas para auxiliar a interpretação estrutural e para a localização de afloramentos.

\section{Caracterização de mesoestruturas}

Nesta etapa, estruturas em mesoescala foram caracterizadas em campo, com a coleta de atitudes de estruturas sedimentares (acamamentos e paleocorrentes) e estruturas tectônicas (fraturas, falhas e bandas de deformação, com discriminação de cinemática quando possível), além de lineações e foliações no embasamento. A caracterização das estruturas foi feita de acordo com a sua geometria, o espaçamento e os tipos de preenchimento. Para estabelecer a cronologia dos eventos tectônicos, considerou-se as relações de interseção/superposição entre diferentes sistemas de falhas/fraturas/bandas de deformação, a eventual superposição de slickenlines e as unidades litoestratigráficas afetadas. Na ausência de feições cataclásticas, as bandas de deformação podem ser relacionadas a estágios pré- a sin-litificação das rochas sedimentares, o que pode auxiliar na inferência da cronologia dessas estruturas.

Os dados de falhas e slickenlines foram tratados de forma estatística no software Win-TENSOR versão 5.0.1 (Delvaux e Sperner, 2003), com o qual foram produzidos diagramas estereográficos para a análise da orientação dos esforços associados a essas estruturas.

\section{ANÁLISE E INTERPRETAÇÃO DE MACROESTRUTURAS}

Nos terrenos cristalinos adjacentes à borda oeste da Bacia do Parnaíba, os lineamentos obedecem ao trend $\mathrm{N}-\mathrm{S}$, variando para NW e NE (Figura 3), sendo relacionadas ao Ciclo Brasiliano na Faixa Araguaia (Herz et al., 1989). Na porção SSE da área de trabalho foi identificado, nos produtos de sensor remoto, um segmento do Lineamento Transbrasiliano que adentra no substrato da bacia. Essa estrutura é também relacionada à orogênese Brasiliana (Delgado et al., 2003).

Os fotolineamentos N-S no interior da bacia devem ter sido originados através de reativações de anisotropias pré-cambrianas durante a implantação dos grabens estudados. Fotolineamentos com direção NW, na Faixa Araguaia, correspondem a zonas de cisalhamento tardias do Ciclo Brasiliano e podem ter controlado os fotolineamentos com esse trend.
Essas estruturas são observadas por toda a área estudada, mostrando orientação variável $\left(10-20^{\circ}\right)$, porém concentrada na direção N-S (Figura 4). Estes são os fotolineamentos mais expressivos e mais extensos, ocorrendo principalmente na porção centro-norte da área, desde o paralelo de Xambioá até a cidade de Colinas do Tocantins, e daí continuando até a região de Palmas, acompanhando o trend estrutural da FA. Os lineamentos que delimitam as bordas leste e oeste do Graben de Araguaína estão assinalados com setas ( $\left.{ }^{\circ} 1\right)$ na Figura 3. Em campo, os mesmos correspondem a falhas normais, e subordinadamente de rejeito oblíquo, ocorrendo (e/ou delimitando) nas unidades de idade paleozoica e, em especial, na sequência Neocarbonífera-Eotriássica. A disposição das faixas aflorantes das unidades litoestratigráficas, paralelas a esses lineamentos N-S, incluindo contatos anômalos, caracterizam a estruturação do Graben de Araguaína. Essas falhas também justapõem as unidades sedimentares com o embasamento cristalino.

O Graben do Muricizal, a oeste da BPar, também é condicionado pelos fotolineamentos de direção N-S, que são interpretados como falhas de regime normal, delimitando os contatos entre o embasamento cristalino e a Formação Motuca, pertencente à sequência Neocarbonífera-Eotriássica. É possível que unidades mais antigas ocorram no interior do graben. Este graben é segmentado, com outra parte dessa estrutura localizada mais a sul, na altura da cidade de Miracema do Tocantins.

Os fotolineamentos de direção NE estão presentes principalmente na região sul/sudeste da área, entre as cidades de Taquarussu do Tocantins e Ponte Alta do Tocantins. Essas estruturas associam-se, em campo, a falhas normais ou de rejeito oblíquo que afetam desde a Sequência Siluriana até a Sequência Neocarbonífera-Eotriássica, bem como o embasamento cristalino. Deve ser observada a sua orientação coincidente com o trend NE do Lineamento Transbrasiliano, evidenciando a sua reativação no interior da bacia.

As estruturas de direção E-W e/ou ENE a ESE se concentram nas proximidades das cidades de Babaçulândia e Wanderlândia. Em campo, são associadas a falhas e bandas de deformação de regime normal. Afetam principalmente a Formação Sambaíba e a Suíte Mosquito, mas também as unidades paleozoicas. Este conjunto de fotolineamentos deve ser mais novo que a implantação do Graben de Araguaína visto que, na imagem SRTM, os mesmos truncam a estruturação $\mathrm{N}-\mathrm{S}$ na região de Wanderlândia (seta $\mathrm{n}^{\circ} 2$, Figura 3 ).

Os fotolineamentos de direção NW concentram-se

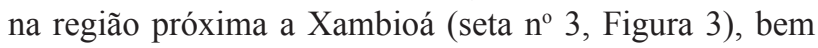
como, de modo mais esparso, na borda da bacia entre os paralelos de Colinas do Tocantins e Paraíso do Tocantins, impressos no embasamento cristalino mas também exibindo continuidade no interior da bacia. Em campo, relacionam-se a falhas normais (afetando principalmente a Sequência Neocarbonífera-Eotriássica) ou de rejeito direcional (afetando principalmente a Sequência Mesodevoniana-Eocarbonífera). 


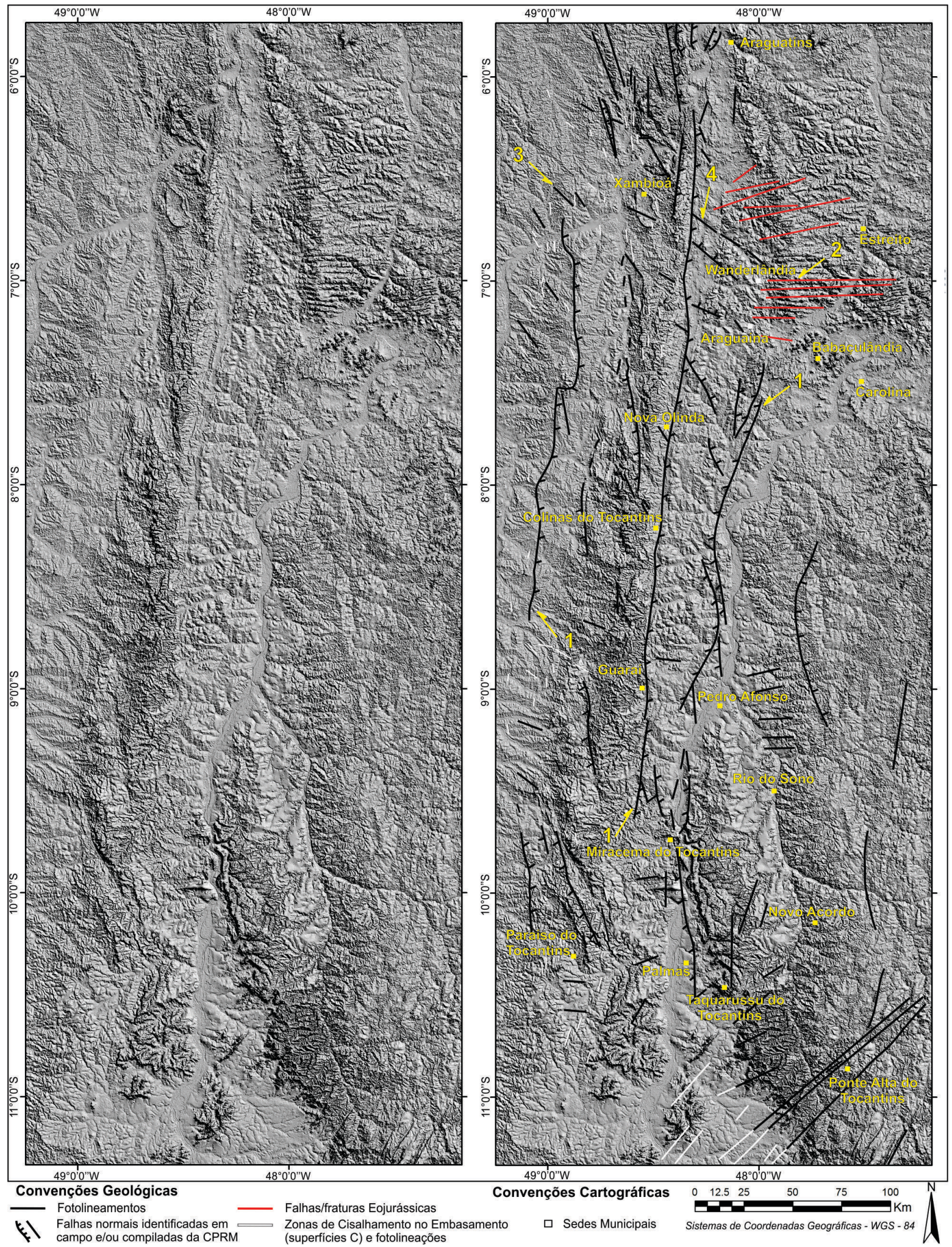

Figura 3. Imagens SRTM com iluminação artificial (azimute solar: $45^{\circ}$ e inclinação solar: 45). Em (1) observa-se a delimitação dos grabens através de falhas normais conferidas em campo. (2) Exemplifica fotolineamentos que truncam a estruturação associada aos grabens. (3) Exemplifica fotolineamentos de direção NW, associados ao embasamento cristalino. (4) Indicação de estruturas de direção NW que penetram na bacia. Uma versão desta figura, em maior detalhe, pode ser consultada em Souza (2016). 


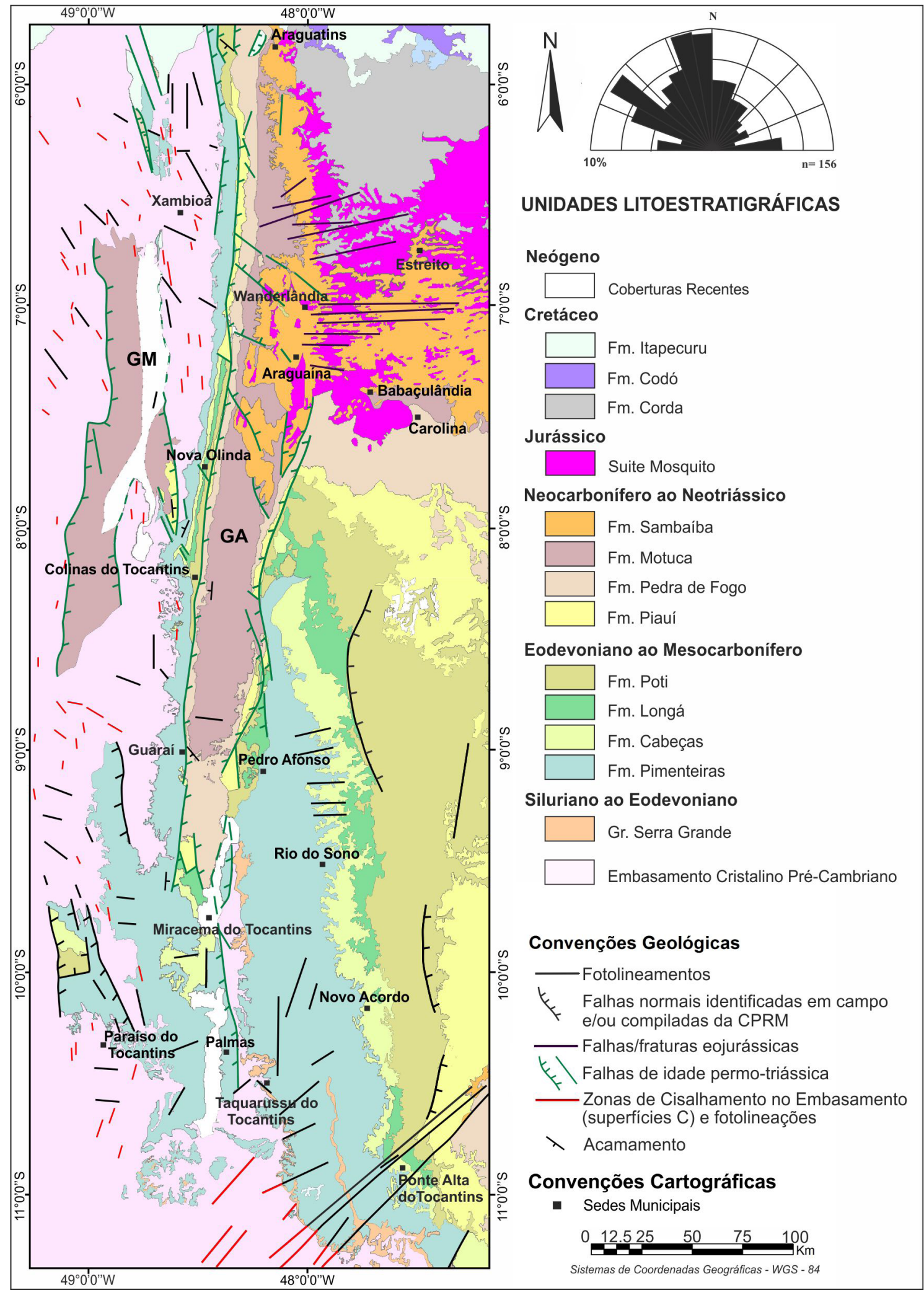

Figura 4. Mapa geológico da área de estudo com fotolineamentos traçados. Diagrama de rosetas (por frequência) geradas a partir dos fotolineamentos. Base cartográfica e geológica da CPRM (Faraco et al., 2004a, 2004b; Vasconcelos et al., 2004a, 2004b) com modificações nas cores das unidades. GA - Graben de Araguaína. GM - Graben do Muricizal. Uma versão desta figura, em mais detalhe, pode ser consultada em Souza (2016). 
Essas estruturas acompanham o trend que vem do embasamento cristalino (extraídos como fotolineações que representam zonas de cisalhamento) e penetram na bacia como estruturas rúpteis (falhas e/ou fraturas), observadas nas imagens orbitais, conforme sinalizado pela seta $n^{\circ} 4$, na Figura 3 .

\section{CARACTERIZAÇÃO TECTONO-ESTRATIGRÁFICA DO SISTEMA DE GRABENS DO RIO TOCANTINS}

A borda oeste da BPar apresenta estruturas que a diferenciam do contexto dominante na bacia. Destacam-se duas estruturas do tipo graben (de Araguaína e Muricizal, doravante referidos como GA e GM, respectivamente, como pode ser visto na Figura 4), que compõem o sistema de grabens em estudo, a primeira já no interior da bacia, a segunda implantada diretamente sobre o embasamento cristalino (Faixa Araguaia). As mesmas são delimitadas por falhas $\mathrm{N}-\mathrm{S}$, com variação de $20^{\circ}-30^{\circ}$ para leste e oeste. Na porção norte da região, fotolineamentos E-W/ENE proeminentes estão associados aos derrames e soleiras da Suíte Mosquito e cruzam a estrutura N-S do Graben de Araguaína.

$\mathrm{Na}$ área do GA, as unidades do Grupo Balsas assumem a disposição alongada N-S desta estrutura, em contraposição ao padrão regional mais a leste, em arco E-W a ENE, característico da bacia (como mostra a Figura 2). Os grupos Serra Grande e Canindé afloram nos altos laterais e ocorrem sotopostos, no interior do GA. Nas bordas do GA é possível observar rochas do Grupo Canindé, com contatos dispostos na direção N-S, coincidentes com fotolineamentos e omitindo unidades ou camadas, inclusive do Grupo Balsas (observadas em mapa, Figura 4), diagnosticando falhas normais ao longo deste trend. Na borda oeste, uma fina seção de arenitos correlatos ao Grupo Serra Grande ocorre localmente, o que pode implicar forte erosão anterior ao Grupo Canindé, evidenciando a discordância eodevoniana nominada por Vaz et al. (2007).

No horst a leste do GA, na região entre Miracema do Tocantins e a sul de Palmas, o Grupo Serra Grande (aqui mais espesso) e o embasamento cristalino são soerguidos pelas falhas N-S e afloram no interior da bacia, já próximo à terminação sul desta estrutura (Figura 5).

\section{Eventos deformacionais e cinemática das estruturas do sistema de Grabens do Rio Tocantins}

$\mathrm{Na}$ área de estudo, três eventos deformacionais $\left(\mathrm{D}_{1}, \mathrm{D}_{2}\right.$ e $\left.\mathrm{D}_{3}\right)$ foram caracterizados com base na assinatura cinemática e marcadores cronoestratigráficos associados. $\mathrm{O}$ primeiro deles é relacionado à geração do sistema de grabens $\mathrm{N}-\mathrm{S}$ (GA e GM). Nos mapas da bacia (Figura 4), as exposições da Formação Motuca (de idade eotriássica), bem como as unidades sotopostas, encontram-se inteiramente controladas pela estrutura N-S dos grabens, o que também ocorre com uma porção da Formação Sambaíba na região de Araguaína e Wanderlândia (Figuras 3 e 4). Essas observações conferem uma idade mínima Eo- a Mesotriássica para a formação dos grabens. As fácies fluviais da Formação Pedra de Fogo apresentam paleocorrentes para o interior dessa estrutura, enquanto que as fácies flúvio-lacustres da Formação Motuca mostram direções de paleocorrentes, também no interior do GA, paralelas ao eixo N-S do mesmo. Estas observações sugerem um controle estrutural na deposição destas unidades nesta região da borda oeste da bacia e fortalecem a idade mínima permiana-eotriássica presumida para esses grabens.

Os demais eventos deformacionais são considerados mais jovens. $\mathrm{O}$ segundo deles $\left(\mathrm{D}_{2}\right)$ está associado às estruturas distensionais de direção E-W/ENE que também afetam/controlam o magmatismo Mosquito, de idade Eojurássica. Finalmente, o terceiro evento $\left(\mathrm{D}_{3}\right)$ é caracterizado por uma cinemática distensiva de direção NW.

\section{O Evento Deformacional $D_{1}$}

As estruturas que definem este evento foram observadas nas três sequências sedimentares que ocorrem na região. Contudo, uma maior frequência destas é observada nos

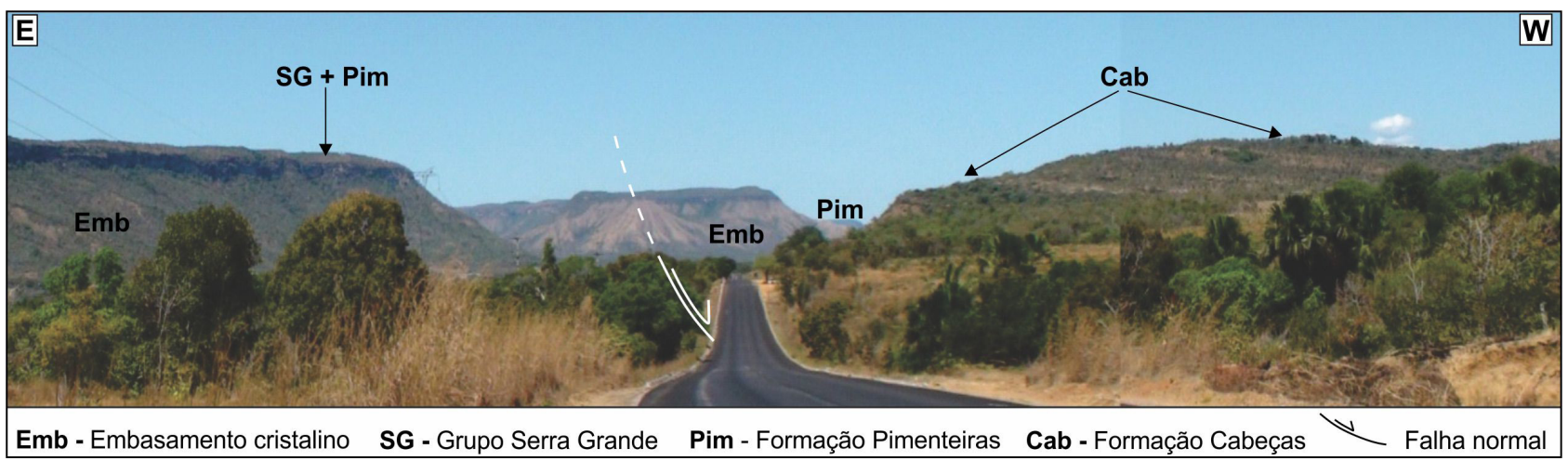

Figura 5. Visão panorâmica da terminação sul do Graben de Araguaína, mostrando a relação lateral entre dois grupos de idades distintas (Serra Grande e Canindé, este último representado pelas formações Pimenteiras e Cabeças). 
grupos Canindé e Balsas, em função de sua área aflorante mais expressiva. Este evento caracteriza a borda oeste da BPar, envolvendo a influência de anisotropias prévias do embasamento pré-cambriano (a Faixa Araguaia), reativadas quando submetidas a um novo campo de esforços. No geral, a deformação gerou um conjunto de estruturas de mergulho médio a forte e slickenlines de rake moderado a alto, representado falhas normais oblíquas (componente sinistral) N-S, e por falhas normais orientadas em torno de NW-SE a N-S (Figura 6A e B e Figura 7i), além de bandas de deformação com rejeito normal e direção N-S a NNE-SSW (Figura 7ii). O campo de strain responsável por esta deformação, determinado com base nos planos de falhas/bandas de deformação e respectivos slickenlines, mostra eixo de distensão $\mathrm{X}$ com direção NE-SW (Figura 7iii). Em relação às falhas N-S que limitam os grabens, a direção de distensão inferida indica uma abertura oblíqua, resultando em componente direcional sinistral, que é consistente com falhas de rejeito direcional sinistral, direção NE a ENE, observadas em afloramento na região de Ponte Alta do Tocantins (ilustração na Figura 6C). $\mathrm{O}$ acamamento de algumas formações (Pimenteiras, Pedra de Fogo e Motuca) que estão nas proximidades das falhas
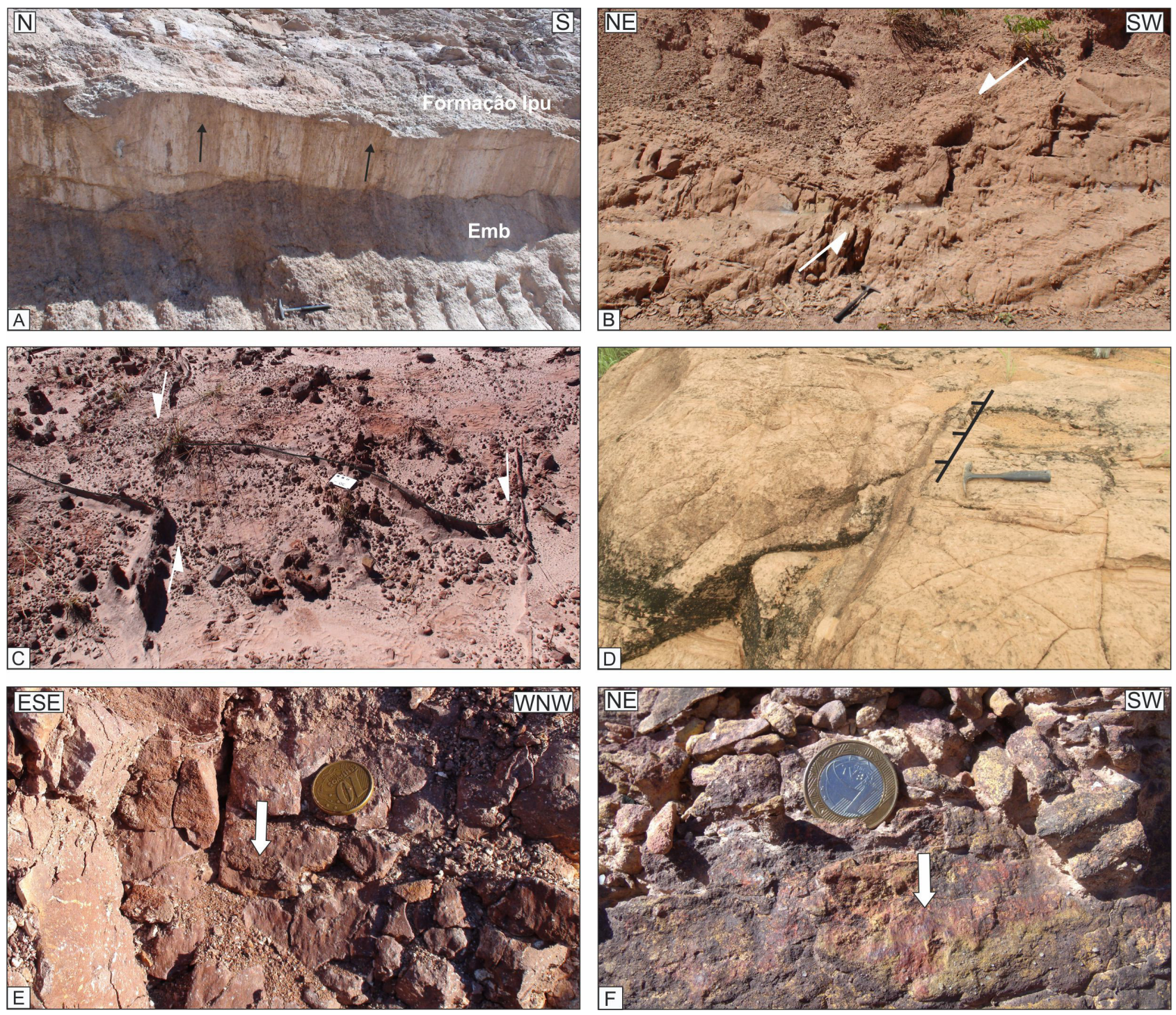

Figura 6. Estruturas relacionadas aos diversos eventos deformacionais. (A) Falha normal de direção N-S, que afeta arenitos da Formação Ipu, colocados em contato com o embasamento cristalino (observar slickenlines). (B) Falha normal de direção NW-SE em arenitos da Formação Poti. (C) Falha transcorrente sinistral de direção NE em arenitos da Formação Pimenteiras; (A, B, C) são estruturas $D_{1}$. (D) Banda de deformação normal de direção ESE, observada em arenitos da Formação Motuca. (E) Plano de falha normal com direção ESE em basaltos da Suíte Mosquito; (D) e (E) são estruturas D . $^{2}$ (F) Plano de falha normal com direção NE em diamictitos da Formação Cabeças, essa estrutura é de idade $D_{3}$. Nas fotos, o cabo do martelo aponta para o norte. 
de borda do Graben de Araguaína apresenta alto ângulo de mergulho (Figura 6A). O Graben do Muricizal também é relacionado a este evento, dado à sua similaridade em orientação e preenchimento sedimentar.

Este regime deformacional pode ser correlacionado ao modelo proposto por Santos et al. (2015), quando os mesmos caracterizam uma reativação transcorrente sinistral de idade neopermiana, na porção SW do Lineamento Transbrasiliano na BPar. Essa deformação seria compatível com o campo de strain associado aos grabens N-S. A abertura do Graben de Araguaína com distensão NE ocorreu em época equivalente, com base na sua compatibilidade de cinemática e em termos de idades das formações afetadas e/ou controladas pela estruturação descrita.

\section{O Evento Deformacional $D_{2}$}

Este evento é basicamente expresso por estruturas que refletem distensão em alto ângulo em relação àquela do evento $\mathrm{D}_{1}$. Essas estruturas são encontradas nas porções interna e externa (a leste) do Graben de Araguaína. Os três grupos paleozoico-neotriássicos (Serra Grande, Canindé e Balsas), além da Suíte Mosquito, são afetados pelas mesmas, o que permite inferir uma idade Eojurássica para o evento. Na porção norte da área, as estruturas $\mathrm{D}_{2}$ claramente interceptam o trend N-S do Graben de Araguaína. São observadas falhas normais de direção E-W com variação para ENE e ESE, e bandas de deformação de direção aproximada E-W (Figura 6D, E; Figura 7iv e 7v). A partir da análise dos planos

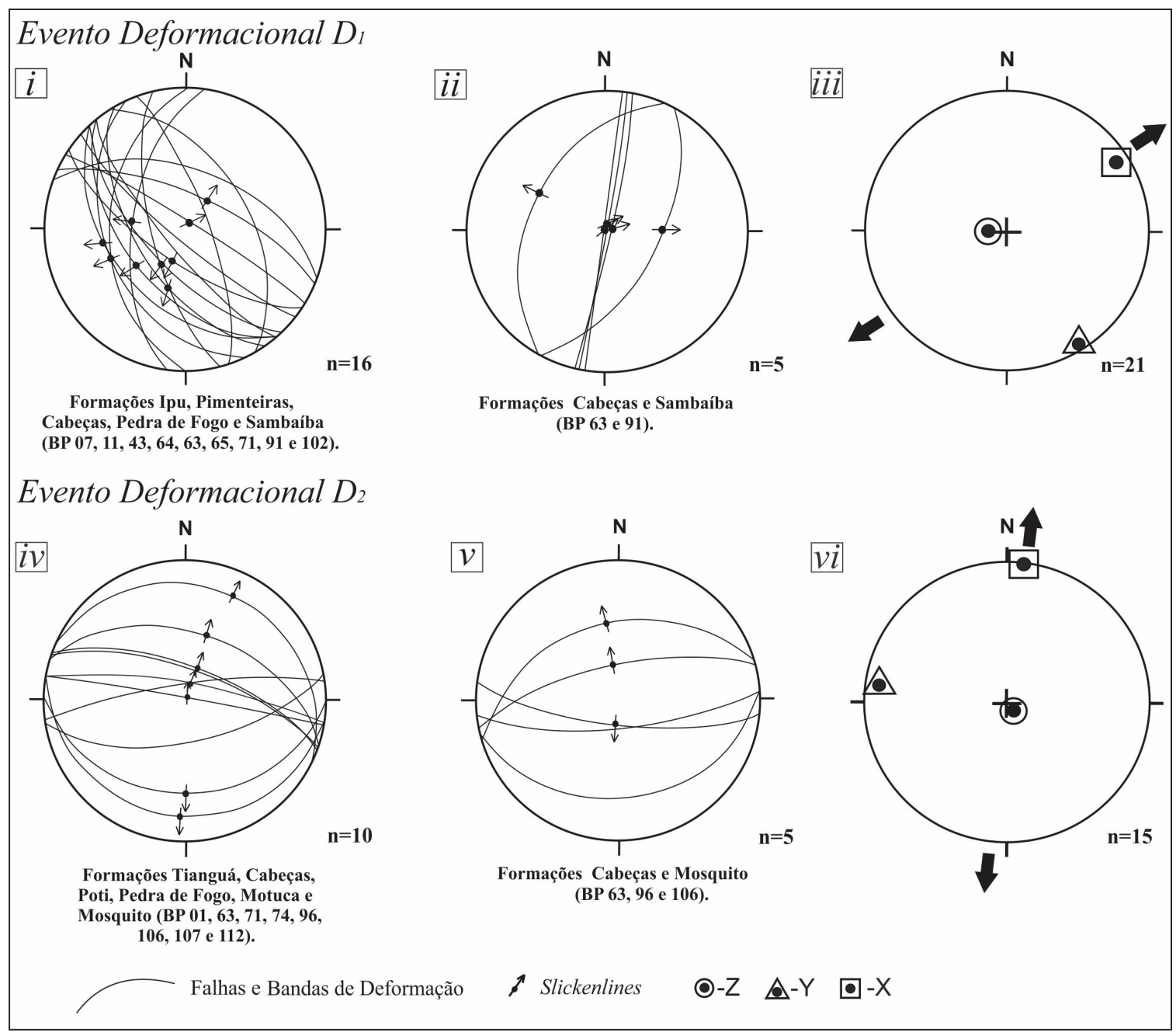

Figura 7. Projeções estereográficas geradas no programa Win-Tensor (projeção Schmidt-Lambert, hemisfério inferior) para os sistemas de falhas relacionados às fases deformacionais $D_{1}$ e $D_{2}$. (i) Falhas normais com direção NW e falhas normais oblíquas N-S com componente sinistral. (ii) Bandas de deformação NNE-SSW. (iii) Reconstrução cinemática para o sistema de falhas e bandas de deformação da fase $D_{1}$, onde o eixo de distensão $(X)$ possui direção NE-SW. (iv) Falhas normais de direção E-W, ENE e ESE. (v) Bandas de deformação com orientação tendendo a E-W. (vi) Reconstrução cinemática para o sistema de falhas da fase $D_{2}$, na qual o eixo de encurtamento $(Z)$ está praticamente vertical e o eixo de distensão (X) possui direção NNE-SSW. Setas pretas indicam o eixo de distensão horizontal. 
das falhas, bandas de deformação e respectivos slickenlines, foi possível estabelecer um campo de strain com eixo de distensão X, NNE-SSW (Figura 7vi).

Este evento é associado ao magmatismo básico toleítico (incluindo o alojamento de corpos básicos que seguem o trend E-W) da Suíte Mosquito e de unidades similares em outras bacias paleozoicas no norte do Brasil, sendo relacionado ao evento de rifteamento do Atlântico Central (Thomaz Filho et al., 2000).

\section{O Evento Deformacional $D_{3}$}

As estruturas geradas neste último evento incluem falhas de rejeito normal e de rejeito direcional, as quais atingiram majoritariamente as unidades dos grupos Canindé e Balsas, de maior extensão aflorante. Estruturas $\mathrm{D}_{3}$ são representadas por falhas normais NE-SW (Figura 6F; Figura 8i), falhas de rejeito direcional sinistral com orientação WNW-ESE (Figura 8ii) e falhas de rejeito direcional dextral com orientação variando entre NW a N-S (Figura 8iii). Com a análise de todos os planos de falhas e seus respectivos slickenlines foi possível inferir um campo de strain com eixo de distensão X, de direção NW-SE (Figura 8iv); nesta fase, o eixo de distensão pode ter sofrido pequena variação de NNW para WNW. Por outro lado, a ocorrência tanto de falhas normais como transcorrentes/de rejeito direcional é creditada a efeitos de permutação na orientação espacial dos eixos de strain $\mathrm{Y}$ e Z, mas mantendo a mesma orientação da distensão X.

Regionalmente, este evento é tentativamente correlacionado ao rifteamento do Atlântico Sul, caracterizado por sua assinatura estrutural análoga àquela registrada na Província

\section{Evento Deformacional $D_{3}$}

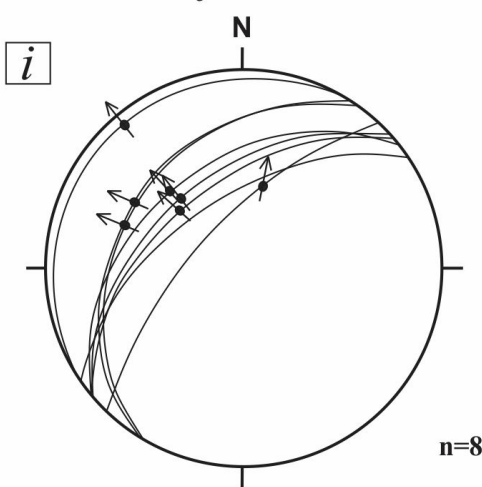

Formações Pimenteiras e Cabeças (BP 21 e 63).

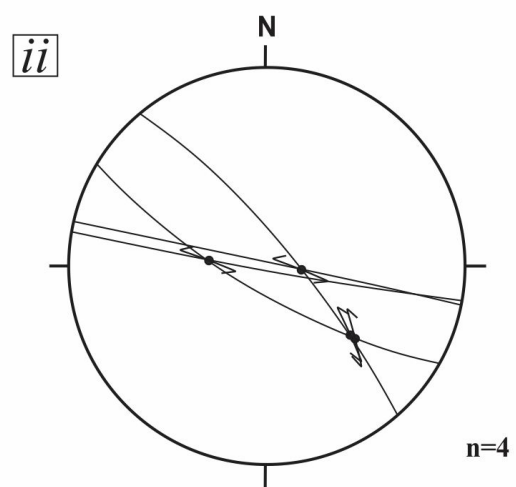

Formações Pimenteiras, Pedra de Fogo e Motuca (BP 43, 65, 71 e73).

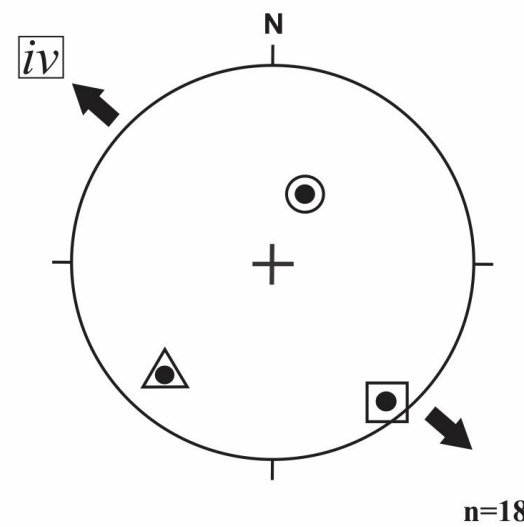

$\mathbf{n}=18$ iii

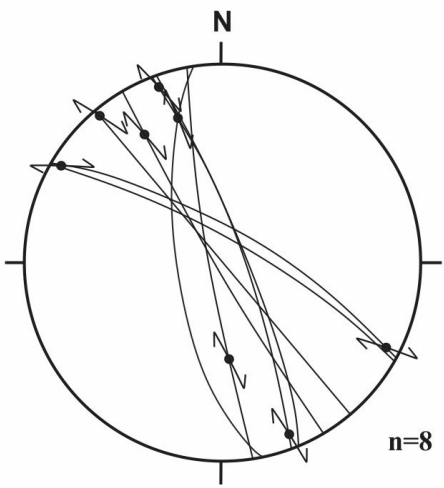

Formações Pimenteiras, Pedra de Fogo, Motuca e Mosquito (BP 07, 65, 73 e 107).

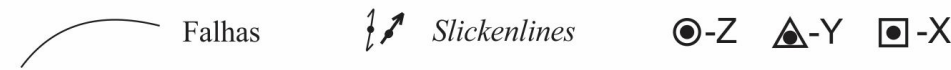

Figura 8. Projeções estereográficas geradas no programa Win-Tensor (projeção Schimidt-Lambert, hemisfério inferior) para o sistema de falhas relacionadas à fase deformacional $\mathrm{D}_{3}$. (i) Falhas normais de direção NE-SW. (ii) Falhas de rejeito direcional sinistral com direção WNW-ESE. (iii) Falhas de rejeito direcional dextral com direção NW-SE e NNE-SSW. (iv) Reconstrução cinemática para o sistema de falhas da fase $D_{3}$, onde o eixo de distensão $(X)$ possui direção NW-SE. Setas pretas indicam o eixo de distensão horizontal. 
Borborema durante o Neocomiano-Barremiano, a qual está associada à gênese dos grabens do trend Cariri-Potiguar (Matos, 1999).

\section{CONCLUSÕES}

O artigo apresenta uma análise de lineamentos e de dados estruturais de campo, que fornece elementos para melhorar o conhecimento do importante Sistema de Grabens do Rio Tocantins, com direção N-S, incluindo o Graben de Araguaína (GA) e o Graben do Muricizal (GM). Estas estruturas localizam-se na borda oeste da Bacia do Parnaíba, já tendo sido reconhecidas em trabalhos precedentes. O GA possui comprimento aflorante da ordem de $400 \mathrm{~km}$, entre os paralelos de Araguatins (TO) e Taquarussu do Tocantins (TO), e largura na ordem de 40 a $50 \mathrm{~km}$. As falhas N-S com componente normal se estendem por pelo menos 50 a $60 \mathrm{~km}$ cada, a leste e oeste do GA. O GM possui na ordem de $200 \mathrm{~km}$ de comprimento e largura da ordem de 25 a $50 \mathrm{~km}$,

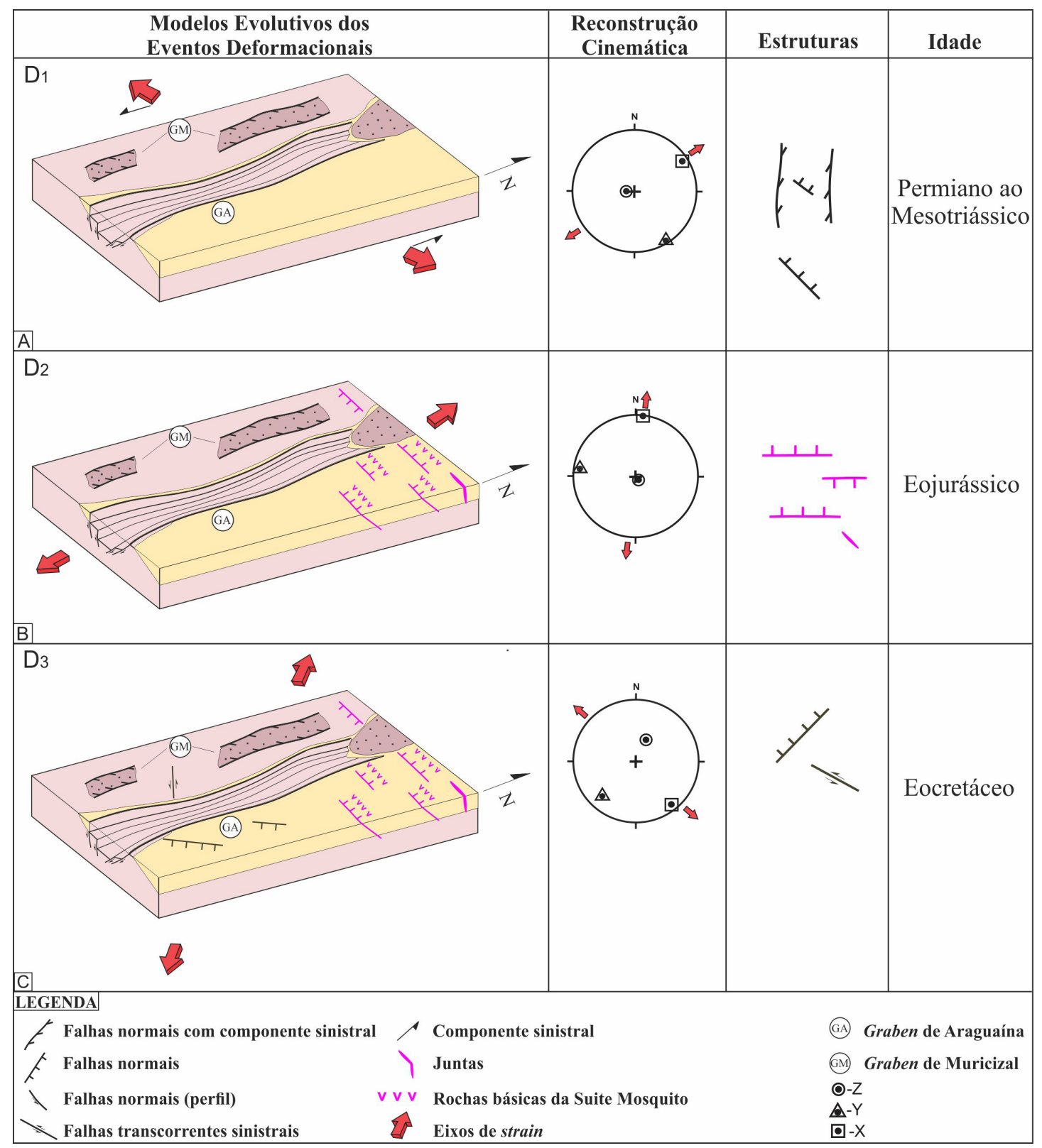

Figura 9. Modelo evolutivo para o Sistema de Grabens do Rio Tocantins (SGRT), os blocos diagramas ilustram a geometria e cinemática do evento de formação do graben. (A) Distensão oblíqua no Permiano-Triássico Médio, e fases deformacionais subsequentes que afetaram a Bacia do Parnaíba. (B) Distensão N-S associada com o evento magmático Mosquito, no Jurássico Inferior. (C) Distensão NW correlacionada à abertura do Atlântico Sul, no Cretáceo Inferior. 
e seu outro segmento possui aproximadamente $70 \mathrm{~km}$ de comprimento e $25 \mathrm{~km}$ de largura. O desenvolvimento dos grabens é interpretado como tendo ocorrido entre o Permiano e o Mesotriássico, com base no padrão de afloramentos das unidades litoestratigráficas no seu interior e nos sistemas de paleocorrentes de algumas dessas unidades.

Os dados coletados na região do Graben de Araguaína permitiram definir três eventos deformacionais. Inicialmente, a estruturação do graben teve inicio com o evento $\mathrm{D}_{1}$ e, subsequentemente, houve a ação de dois outros eventos $\left(\mathrm{D}_{2}\right.$ e $\left.\mathrm{D}_{3}\right)$ que afetaram a região.

$\mathrm{O}$ evento deformacional $\mathrm{D}_{1}$ seria resultado de um campo de strain com eixo de distensão X, NE-SW, gerando falhas normais a normais obliquas (componente direcional sinistral) predominantemente orientadas entre N-S a NW, e subordinadamente a NNE. O controle destas falhas na deposição de sedimentos das formações Pedra de Fogo e Motuca é atestado pelos dados de paleocorrentes que exibem sentidos para o interior do graben e paralelas ao seu eixo $\mathrm{N}-\mathrm{S}$, respectivamente. Em decorrência, é inferida uma idade Permiana, com provável extensão ao Mesotriássico Médio, a julgar pela ocorrência de bandas de deformação N-S na Formação Sambaíba.

Os dados obtidos indicam que existe uma compatibilidade desse evento com o campo de strain gerado a partir de uma reativação transcorrente sinistral no Lineamento Transbrasiliano (LTB), durante o Permiano, proposta por Santos et al. (2015). Estes dados sugerem uma possível ligação entre essas duas macroestruturas (LTB e Sistema de Grabens do Rio Tocantins, SGRT), no que diz respeito à abertura do graben durante o Permo-Triássico (Figura 9).

$\mathrm{O}$ evento deformacional $\mathrm{D}_{2}$ é relacionado a uma distensão de direção geral N-S (variando de NNE a NNW). A idade relativa deste evento é dada pelo truncamento das falhas normais de direção N-S (de $\left.\mathrm{D}_{1}\right)$ pelas estruturas distensionais E-W. Em adição, as estruturas E-W são mais expressivas na Formação Sambaíba e controlam os corpos de diabásio da Suíte Mosquito, conferindo uma idade eojurássica para este evento, provavelmente relacionado à abertura do oceano Atlântico Central (Tomaz-Filho et al., 2000).

$\mathrm{O}$ último evento deformacional $\left(\mathrm{D}_{3}\right)$ apresenta eixo de distensão X com direção NW-SE. Este evento pode ser correlacionado ao campo de strain que controlou o rifteamento na Província Borborema durante o Neocomiano-Barremiano, quando da abertura do Atlântico Sul (Matos, 1999).

\section{AGRADECIMENTOS}

Que fiquem registrados os agradecimentos dos autores à CHEVRON/BRASIL, que, em convênio com a UFRN/PPGG/FUNPEC, financiou este trabalho no âmbito do projeto de pesquisa 'Geologia e Sistemas Petrolíferos da Bacia Intracratônica do Parnaíba, Nordeste do Brasil'.
O primeiro autor agradece a concessão da bolsa de mestrado pela CAPES, vinculada ao Programa de Pós-Graduação em Geodinâmica e Geofísica (PPGG) da Universidade Federal do Rio Grande do Norte (UFRN). Finalmente, os autores do trabalho são gratos pelas discussões visando o aperfeiçoamento deste texto, além dos revisores deste artigo, Gustavo Viegas e os anônimos.

\section{REFERÊNCIAS}

Abreu, F. A. M. (1978). Estratigrafia e evolução estrutural do segmento setentrional da Faixa de Dobramentos Paraguai-Araguaia. Dissertação (Mestrado). Belém: Centro de Geociências, UFPA.

Almeida, F. F. M., Carneiro, C. D. R. (2004). Inundações marinhas fanerozoicas no Brasil e recursos minerais associados. In: V. Mantesso Neto, A. Bartorelli, C. D. R. Carneiro, B. B. Brito Neves (Eds.), Geologia do continente sul-americano: evolução da obra se Fernando Flávio Marques de Almeida, 43-48. São Paulo: Ed. Beca.

Araújo, V. A. (2001). Programa de Levantamentos Geológicos Básicos do Brasil-PLGB. Araguaina -Folha SB.22-Z-D, Estados do Tocantins e do Pará. Escala 1:250.000. (Organizado por Vanderlei Antônio de Araújo e Odair Olivatti). Brasília: CPRM/DIEDIG/DEPAT.

Cordani, U. G., Teixeira, W., D’Agrella, M. S., Trindade, R. I. (2009). The position of the Amazonian Craton in supercontinents. Gondwana Research, 15, 396-407.

Cunha, F. M. B. (1986). Evolução Paleozoica da Bacia do Parnaiba e seu arcabouço tectônico. Dissertação (Mestrado). Rio de Janeiro: UFRJ.

Delgado, I. M., Souza, J. D., Silva, L. C., Silveira Filho, N. C., Santos, R. A., Pedreira, A. J., Guimarães, J. T., Angelim, L. A. A., Vasconcelos, A. M., Gomes, I. P., Lacerda Filho, J. V., Valente, C. R., Perrotta, M. M., Heineck, C. A. (2003). Geotectônica do Escudo Atlântico. In: L. A. Bizzi, C. Schobbenhaus, R. M. Vidotti, J. H. Gonçalves (Eds.), Geologia, Tectônica e Recursos Minerais do Brasil, 227334. Brasília: CPRM.

Delvaux, D., Sperner, B. (2003). Stress tensor inversion from fault kinematic indicators and focal mechanism data: the TENSOR program. In: New Insights into Structural Interpretation and Modelling, 75-100. London: Geological Society, (Geological Society Special Publications, 212).

Faraco, M. T. L., Frasca, A. A., Marinho, P. A. C., Vale, A. G., Costa, E. J. S., Maria, R. G. N., Ferreira, A. L., Valente, C. R., Lacerda Filho, J. V., Moreton, L. C., Ribeiro, P. S. E., Camargo, L. C., Camargo, M. A., Vasconcelos, A. M., Oliveira, M., Oliveira, I. W. B., Abreu Filho, W. A., Gomes, 
I. P. (2004a). Folha SC.22 - Tocantins. In: C. Schobbenhaus, J. H. Gonçalves, J. D. S. Santos, M. B. Abram, R. Leão Neto, G. M. M. Matos, R. M. Vidotti, M. A. B. Ramos, J. D. A. Jesus (Eds.), Carta Geológica do Brasil ao Milionésimo, Sistema de Informações Geográficas. Programa de Geologia do Brasil. Brasília: CPRM. CD-ROM.

Faraco, M. T. L., Marinho, P. A. C., Vale, A. G., Costa, E. J. S., Maria, R. G. N., Ferreira, A. L., Valente, C. R., Lacerda Filho, J. V., Moreton, L. C., Camargo, M. A., Vasconcelos, A. M., Oliveira, M., Oliveira, I. W. B., Abreu Filho, W. A., Gomes, I. P. (2004b). Folha SB.22 - Araguaina. In: C. Schobbenhaus, J. H. Gonçalves, J. D. S. Santos, M. B. Abram, R. Leão Neto, G. M. M. Matos, R. M. Vidotti, M. A. B. Ramos, J. D. A Jesus (Eds.), Carta Geológica do Brasil ao Milionésimo, Sistema de Informações Geográficas. Programa de Geologia do Brasil. CPRM: Brasília. CD-ROM.

Góes, A. M. (1995). A Formação Poti (Carbonífero Inferior) da Bacia do Parnaíba. Tese (Doutorado). São Paulo: Instituto de Geociências - USP.

Gorayeb, P. S. S. (1981). Evolução geológica da região de Araguacema-Pequizeiro, Goiás, Brasil. Dissertação (Mestrado). Belém: Centro de Geociências - UFPA.

Herz, N., Hasui, Y., Sena Costa, J. B., Matta, M. A. S. (1989). The Araguaia Fold Belt, Brazil: A Reactivated BrasilianoPan-African Cycle (550 Ma) Geosuture. Precambrian Research, 42, 371-386.

Matos, R. M. D. (1999). History of the northeast Brazilian rift system: kinematic implications for the break-up between Brazil and West Africa. In: N. R. Cameron, R. H. Bate, V. S. Clure (Eds.), The oil and gas habitats of the South Atlantic, 55-73. (Geological Society Special Publication, 153).

Sadowski, G. R., Cruz Campanha, G. A. (2004). Grandes Falhas no Brasil Continental. In: V. Mantesso-Neto, A. Bartorelli, C. D. R. Carneiro, B. B. Brito-Neves (Eds.), Geologia do Continente Sul-Americano: Evolução da Obra de Fernando Flávio Marques de Almeida, 410. São Paulo: Ed. Beca.
Santos, C. H. O., Jardim de Sá, E. F., Alves da Silva, F. C. (2015). Expressão estrutural do Lineamento Transbrasiliano na porção sudoeste da Bacia do Parnaíba. XXVI Simpósio de Geologia do Nordeste, 191. Natal, Brasil.

Souza, K. S. (2016). Análise Estrutural do Sistema de Grabens do Rio Tocantins, Borda Oeste da Bacia do Parnaíba (Tocantins, Pará e Maranhão). Dissertação (Mestrado). Natal: PPGG, UFRN.

Thomaz-Filho, A., Mizusaki, A. M. P., Milani, E. J., Cesero, P. (2000). Rifting and magmatism associated with the South America and Africa break up. Revista Brasileira de Geociencias, 30, 17-19.

Vasconcelos, A. M., Kosin, M., Ribeiro, J. A. P., Colares, J. Q. S., Gomes, I. P., Forgiarini, L. L., Medeiros, M. F., Souza, J. D., Valente, C. R., Neves, J. P., Heineck, C. A., Lacerda Filho, J. V., Teixeira, L. R., Borges, V. P., Bento, R. V., Guimarães, J. T., Oliveira, I. W. B., Gomes, I. P., Malouf, R. F., Carvalho, L. M., Abreu Filho, W. (2004a). Folha SB.23 - Teresina. In: C. Schobbenhaus, J. H. Gonçalves, J. D. S. Santos, M. B. Abram, R. Leão Neto, G. M. M. Matos, R. M. Vidotti, M. A. B. Ramos, J. D. A. Jesus (Eds.), Carta Geológica do Brasil ao Milionésimo, Sistema de Informações Geográficas. Programa de Geologia do Brasil. Brasília: CPRM. CD-ROM.

Vasconcelos, A. M., Kosin, M., Souza, J. D., Valente, C. R., Neves, J. P., Heineck, C. A., Lacerda Filho, J. V., Teixeira, L. R., Borges, V. P., Bento, R. V., Guimarães, J. T., Oliveira, I. W. B., Gomes, I. P., Malouf, R. F., Carvalho, L. M., Abreu Filho, W. (2004b). Folha SC.22 - Rio São Francisco. In: C. Schobbenhaus, J. H. Gonçalves, J. D. S. Santos, M. B. Abram, R. Leão Neto, G. M. M. Matos, R. M. Vidotti, M. A. B. Ramos, J. D. A. Jesus (Eds.), Carta Geológica do Brasil ao Milionésimo, Sistema de Informações Geográficas. CPRM: Brasília. (Programa de Geologia do Brasil). CD-ROM.

Vaz, P. T., Rezende, N. G. A. M., Wanderley Filho, J. R., Travassos, W. A. (2007). Bacia do Parnaíba. Boletim de Geociências da Petrobrás, 15(2), 253-263. 